\title{
Development of glycinergic innervation to the murine LSO and SPN in the presence and absence of the MNTB
}

\author{
Stefanie C. Altieri ${ }^{1,2}$, Tianna Zhao ${ }^{1}$, Walid Jalabi ${ }^{3}$ and Stephen M. Maricich ${ }^{\text {* }}$ \\ ${ }^{1}$ Richard King Mellon Foundation Institute for Pediatric Research and Department of Pediatrics, University of Pittsburgh, Pittsburgh, PA, USA \\ 2 Department of Otolaryngology, University of Pittsburgh, Pittsburgh, PA, USA \\ ${ }^{3}$ Department of Pediatrics, Case Western Reserve University, Cleveland, OH, USA
}

Edited by:

Conny Kopp-Scheinpflug, Ludwig-Maximilians-University Munich, Germany

\section{Reviewed by:}

Rostislav Turecek, Institute of Experimental Medicine - Academy of Sciences of Czech Republic, Czech Republic

Randy J. Kulesza, Lake Erie College of Osteopathic Medicine, USA

\section{*Correspondence:}

Stephen M. Maricich, Richard King Mellon Foundation Institute for Pediatric Research and Department of Pediatrics, University of Pittsburgh, Pittsburgh, PA 15224, USA e-mail: stephen.maricich@chp.edu
Neurons in the superior olivary complex (SOC) integrate excitatory and inhibitory inputs to localize sounds in space. The majority of these inhibitory inputs have been thought to arise within the SOC from the medial nucleus of the trapezoid body (MNTB). However, recent work demonstrates that glycinergic innervation of the SOC persists in Egr2; En 1 CKO mice that lack MNTB neurons, suggesting that there are other sources of this innervation (Jalabi et al., 2013). To study the development of MNTB- and non-MNTB-derived glycinergic SOC innervation, we compared immunostaining patterns of glycine transporter 2 (GlyT2) at several postnatal ages in control and Egr2; $\mathrm{En}_{1}{ }^{\mathrm{CKO}}$ mice. GlyT2 immunostaining was present at birth (P0) in controls and reached adult levels by P7 in the superior paraolivary nucleus (SPN) and by P12 in the lateral superior olive (LSO). In Egr2; En ${ }^{\mathrm{CKO}}$ mice, glycinergic innervation of the LSO developed at a similar rate but was delayed by one week in the SPN. Conversely, consistent reductions in the number of $\mathrm{GlyT}^{+}$boutons located on LSO somata were seen at all ages in Egr2; En ${ }^{\mathrm{CKO}}$ mice, while these numbers reached control levels in the SPN by adulthood. Dendritic localization of GlyT2+ boutons was unaltered in both the LSO and SPN of adult Egr2; En1 ${ }^{\mathrm{CKO}}$ mice. On the postsynaptic side, adult Egr2; En $1^{\mathrm{CKO}}$ mice had reduced glycine receptor $\alpha 1$ (GlyR $\alpha 1$ ) expression in the LSO but normal levels in the SPN. GlyRa2 was not expressed by LSO or SPN neurons in either genotype. These findings contribute important information for understanding the development of MNTB- and non-MNTB-derived glycinergic pathways to the mouse SOC.

Keywords: hearing, deafness, mouse models, brain development, auditory system

\section{INTRODUCTION}

The pontine superior olivary complex (SOC) is the first central auditory region that receives significant bilateral acoustic information, and it is the primary site for detecting interaural level and timing differences (ILDs and ITDs) critical for sound localization. The neural pathways involved in these processes have been described in detail over the past few decades (Kandler et al., 2009). A critical player in both ILD and ITD detection is the medial nucleus of the trapezoid body (MNTB), which receives glutamatergic input from the contralateral cochlear nucleus $(\mathrm{CN})$ and sends inhibitory projections to ipsilateral SOC nuclei. One major MNTB target is the lateral superior olive (LSO), which participates in ILD processing by integrating these inhibitory inputs with excitatory inputs from the ipsilateral CN (Boudreau and Tsuchitani, 1968; Moore and Caspary, 1983; Spangler et al., 1985; Sanes and Rubel, 1988; Helfert etal., 1989; Bledsoe et al., 1990; Wu and Kelly, 1991, 1992, 1995; Srinivasan et al., 2004). A second major target is the superior paraolivary nucleus (SPN), which also receives excitatory input from contralateral $\mathrm{CN}$ neurons (Friauf and Ostwald, 1988; Helfert et al., 1989; Thompson and Thompson, 1991; Schofield, 1995). The SPN encodes temporal sound features and has been proposed to function in sound localization, rhythm coding, gap detection and/or as a discontinuity detector (Behrend et al., 2002; Dehmel et al., 2002; Kulesza et al., 2003,
2007; Kadner et al., 2006; Kadner and Berrebi, 2008; Felix et al., 2014).

The primary neurotransmitter produced by the MNTB is glycine (Moore and Caspary, 1983; Peyret et al., 1987; Wenthold et al., 1987; Aoki et al., 1988; Helfert et al., 1989; Adams and Mugnaini, 1990). Studies done in many species demonstrate that glycinergic projections to SOC neurons develop during late embryogenesis and mature during the first two weeks of postnatal life, during which their action switches from depolarizing to hyperpolarizing (Wenthold et al., 1987; Helfert et al., 1989; Bledsoe et al., 1990; Sanes and Siverls, 1991; Kandler and Friauf, 1995; Kandler and Gillespie, 2005; Löhrke et al., 2005). In the rat, this switch is mirrored by the appearance and maturation of immunoreactivity for the glycine transporter type 2 (GlyT2; Friauf et al., 1999). Glycinergic network development in the SOC has not been well-studied in mice, where there is functional evidence for faster maturation of the auditory brainstem compared to other species (Ehret, 1976; Kullmann and Kandler, 2001). Understanding these pathways in mice is valuable given the wealth of genetic tools available to manipulate auditory regions for functional and behavioral investigations.

Recent work suggests that glycinergic projections to the SOC arise from additional sources other than the MNTB. Specifically, glycinergic innervation of the SOC is maintained in transgenic 
mice that lack MNTB neurons secondary to $E g r 2^{\mathrm{Cre}}$-mediated conditional deletion of the En1 gene in rhombomeres 3 and 5 (Egr2; En1 ${ }^{\mathrm{CKO}}$ mice; Jalabi et al., 2013). These inhibitory projections are functional but exhibit prolonged inhibitory postsynaptic current (IPSC) decay time constants in both LSO and SPN neurons compared to those seen in control mice. The mechanisms that underlie these differences, as well as the development of these alternative glycinergic projections, have not been studied. Surprisingly, sound localization ability in Egr2; $E n 1^{\mathrm{CKO}}$ mice is relatively preserved, suggesting that remarkable plasticity exists in the developing auditory brainstem.

In this study, we sought to characterize the postnatal development and localization of glycinergic inputs to the LSO and SPN using immunohistochemistry for GlyT2. We also analyzed expression patterns of glycine receptor subtypes Glya1 and Glya 2 in adult control and $E g r 2 ; E n 1^{\mathrm{CKO}}$ mice to see if differences between the two might explain the altered IPSC decay kinetics. Our findings demonstrate that mice lacking MNTB neurons have alterations in the time course of somatic glycinergic innervation in the SPN and in the amount of somatic innervation in the LSO, while dendritic localization of glycinergic terminals is unaltered in both regions. Furthermore, decreased expression of the adult glycine receptor isoform, GlyR $\alpha 1$, was found in the LSO but not SPN of Egr2; En1 ${ }^{\mathrm{CKO}}$ mice.

\section{MATERIALS AND METHODS ANIMALS}

Egr2 $2^{\mathrm{Cre} /+}$ mice (Voiculescu et al., 2000) on a C57BL/6J background were mated with $E n 1^{\text {flox/flox }}$ mice (Sgaier et al., 2007) on a mixed background to produce mice of four genotypes: $E g r 2^{+/+} ; E n 1^{+/ \text {flox }}, E g r 2^{+/+} ; E n 1^{\text {flox } / \text { flox }}, E g r 2^{\mathrm{Cre} /+} ; E n 1^{+/ \text {flox }}$ and $E g r 2^{\mathrm{Cre} /+} ; E n 1^{\text {flox/flox }}$ (Egr2; En1 ${ }^{\mathrm{CKO}}$; Jalabi et al., 2013). As no differences were seen previously between the control genotypes, we used only Egr2 $2^{+/+} ; E n 1^{\text {flox/flox }}$ mice as controls in this study. Brother-sister matings of $E g r 2^{+/+} ; E n 1^{\text {flox/flox }}$ mice and Egr $2^{\mathrm{Cre} /{ }^{+}} ; \mathrm{En} 1^{\text {flox/flox }}$ mice were used to produce offspring. Postnatal day 0 (P0, day of birth), P3, P7, P12, and P14 mice of both sexes were used for early postnatal experiments, while 810 month-old female mice were used for adult experiments $(N=2$ mice/genotype at each age). Mice were maintained and housed on a 12:12 light:dark cycle with access to food and water ad libitum. All procedures were approved by the Case Western Reserve University and University of Pittsburgh Institutional Animal Care and Use Committees.

\section{TISSUE HARVESTING AND PROCESSING}

Mice were deeply anesthetized with $300 \mathrm{mg} / \mathrm{kg}$ Avertin and transcardially perfused with ice-cold $4 \%$ paraformaldehyde (PFA). Whole brains were removed and post-fixed overnight at $4^{\circ} \mathrm{C}$ in $4 \%$ PFA. Following post-fixation, brains were cryoprotected in 30\% sucrose for $48 \mathrm{~h}$. Brains were then embedded in Tissue-Tek O.C.T. compound (Sakura Finetek, Torrance, CA, USA), quickly frozen and stored at $-80^{\circ} \mathrm{C}$ before sectioning. Brains were sectioned in the coronal plane at $10 \mu \mathrm{m}$ thickness using a CM1950 cryostat (Leica, Buffalo Grove, IL, USA). Sections were collected onto Superfrost/Plus slides (Thermo Fisher Scientific), dried overnight and stored in $-80^{\circ} \mathrm{C}$ prior to use. Slide sets with $50 \mu \mathrm{m}$ (adult) or $30 \mu \mathrm{m}$ (young postnatal) separation between sections were prepared to allow systematic sampling through the SOC, and each set was immunostained with a different antibody

\section{IMMUNOHISTOCHEMISTRY}

Slides containing sections through the SOC were rehydrated in $1 \times$ PBS for $5 \mathrm{~min}$ and then incubated in blocking solution (0.3\% Triton X-100, 3\% donkey serum in $1 \times \mathrm{PBS})$ for $1 \mathrm{~h}$. Primary antibodies were diluted in blocking solution and incubated overnight at $4^{\circ} \mathrm{C}$. The following primary antibodies and concentrations were used: guinea-pig anti-glycine transporter 2 (GlyT2) polyclonal antibody (Millipore, Temecula, CA) at 1:1000; chicken anti-MAP2 polyclonal antibody (Abcam Inc., Cambridge, MA, USA) at 1:10000; rabbit anti-glycine receptor alpha 1 (GlyR $\alpha 1)$ polyclonal antibody (Millipore, Temecula, CA, USA) at 1:1000; goat anti-glycine receptor alpha 2 (GlyR $\alpha 2)$ polyclonal antibody at 1:500 (Santa Cruz Biotechnology, Dallas,TX). Slides were washed $3 \times 5 \mathrm{~min}$ in $1 \times$ PBS. Secondary antibodies were diluted in blocking solution at 1:500 and incubated on the slides for $1 \mathrm{~h}$ at room temperature. The following secondary antibodies were used: Alexa Fluor 594-AffiniPure donkey anti-guinea pig, Alexa Fluor 488-AffiniPure donkey anti-chicken, Alexa Fluor 488-AffiniPure donkey anti-rabbit and Alexa Fluor 488-AffiniPure donkey anti-goat (Jackson ImmunoResearch, West Grove, PA). All slides were counterstained with DAPI. Following secondary antibody incubation, slides were washed $3 \times 5$ min in $1 \times$ PBS. In some cases, slides were counterstained with NeuroTrace Green Fluorescent Nissl (Life Technologies, Grand Island, NY) at a concentration of 1:100 diluted in 1× PBS for $30 \mathrm{~min}$ at room temperature. Slides were washed an additional $3 \times 5 \mathrm{~min}$ in $1 \times$ PBS and then mounted with ProLong Gold (Life Technologies, Grand Island, NY). Slides were imaged using a Leica DM5500B epifluorescence microscope or an inverted Zeiss Axio Observer on a PerkinElmer UltraVIEW VoX spinning disk confocal with a Hamamatsu C9100-13 camera and Volocity software.

\section{BOUTON COUNTS AND LOCALIZATION}

GlyT2 + boutons located on LSO and SPN neuron somata of P7, P12 and P14 mice were counted on six sections/side $(N=12$ sections/mouse) on photographs taken at $60 \mu \mathrm{m}$ increments on a Leica DM5500B epifluorescence microscope. For adult mice, bilateral LSO and SPN images across 10 sections/side $(N=20$ sections/mouse) at $50 \mu \mathrm{m}$ increments were used for counting. Images were processed using Image $1.47 \mathrm{~V}(\mathrm{NIH})$, and the number of boutons on all neuronal soma with an identifiable nucleus were counted and reported as mean puncta per neuron \pm SEM. For analyzing localization of glycinergic innervation in the LSO or SPN, boutons were measured by distance from the cell body using Volocity software. The origin of the dendrite $(0 \mu \mathrm{m}$ distance from the soma) was defined as the region where the soma narrowed to form a distinct process. Neurons with an identifiable nucleus and visible dendrites at least $10 \mu \mathrm{m}$ in length were used for analysis ( $N=12$ dendrites/genotype/brain region). Glycine receptor $\alpha 1$ isoform $(\mathrm{GlyR} \alpha 1)$ clusters were quantified by counting the numbers of immunopositive puncta located on 
LSO or SPN neuronal somata $(N=4$ sections/mouse at $50 \mu \mathrm{m}$ increments).

\section{STATISTICAL ANALYSIS}

The number of boutons on LSO or SPN neuronal somata were compared using non-parametric Mann-Whitney $U$ tests for genotype comparisons at the same age and Kruskal-Wallis tests with Dunn's multiple comparisons for age effects within a genotype. The number of boutons located in $5 \mu \mathrm{m}$ segments up to $15 \mu \mathrm{m}$ from the cell soma and the number of GlyR $\alpha 1+$ puncta were compared using Mann-Whitney tests. All statistical analyses were performed using GraphPad Prism software (La Jolla, CA, USA).

\section{RESULTS}

DEVELOPMENT OF GLYCINERGIC PROJECTIONS TO THE SOC OF Egr2; En ${ }^{\text {CKO }}$ MICE AND CONTROL LITTERMATES DIFFERS IN TEMPORAL PATTERNING AND QUANTITY

We immunostained for GlyT2 to label glycinergic projections (Friauf et al., 1999) to the LSO and SPN throughout postnatal development starting on the day of birth (P0). In agreement with previous reports (Jursky and Nelson, 1996; Friauf et al., 1999), diffuse GlyT2 immunoreactivity was present in the LSO of littermate control and Egr2; En1 ${ }^{\mathrm{CKO}}$ mice at $\mathrm{P} 0$ and $\mathrm{P} 3$ (Figures $\left.\mathbf{1} \mathbf{A}_{-} \mathbf{D}^{\prime}\right)$. By P7, distinct boutons were present on cell somata (Figures $1 \mathbf{E}-\mathbf{F}^{\prime}$ ). The number of boutons/soma increased between P7 and P12 in controls $(P<0.04)$ then remained constant at P14 and in adulthood $(9.40 \pm 0.19$ vs. $10.47 \pm 0.16$ vs. $10.63 \pm 0.17$ vs. $10.47 \pm 0.15$, respectively; $N=57-168$ soma from 12 to 20 LSO sections/mouse, $N=2$ mice/age; $P<0.001$ for age effects). The numbers of GlyT2+ boutons/soma also increased with age in Egr2; En1 $1^{\mathrm{CKO}}$ mice $(P<0.001)$, but were consistently 20$30 \%$ lower than control values at P7, P12, P14, and adulthood $(6.73 \pm 0.23$ vs. $7.35 \pm 0.20$ vs. $7.86 \pm 0.18$ vs. $8.25 \pm 0.16$; $N=39-102$ soma from 12 to 20 LSO sections/mouse, $N=2$ mice/age; Figures 1E-M). Thus, glycinergic innervation to the LSO in Egr2; En1 ${ }^{\mathrm{CKO}}$ mice developed following a similar time course to that seen in littermate controls, but never reached control levels.

Similar to the LSO, diffuse GlyT2+ labeling was present in the SPN of P0 and P3 littermate controls and Egr2; En1 ${ }^{\mathrm{CKO}}$ mice (Figures $2 \mathbf{A}_{-} \mathbf{D}^{\prime}$ ). In control mice, the number of boutons/soma remained constant at P7, P12, P14, and adulthood, suggesting that maturation was achieved by the end of the first postnatal week $(11.94 \pm 0.23$, vs. $12.27 \pm 0.22$ vs. $12.86 \pm 0.25$ vs. $13.02 \pm 0.22$, respectively, $N=49-81$ soma from 12 to $20 \mathrm{SPN}$ sections/mouse, $N=2$ mice/age; $P=0.06$ for age effects). In Egr2; En1 ${ }^{\mathrm{CKO}}$ mice, the number of boutons/soma gradually increased from $\mathrm{P} 7$ through $\mathrm{P} 14$ when numbers were similar to adults $(8.63 \pm 0.27,9.30 \pm 0.24,11.92 \pm 0.27$, $12.03 \pm 0.22$, respectively, $N=36-81$ soma from 12 to $20 \mathrm{SPN}$ sections/mouse, $N=2$ mice/age; $P<0.001$ for age effects). While the numbers of boutons/soma were reduced by $25-30 \%$ compared to littermate controls at P7-P14, no differences were detected in adults, suggesting that development of glycinergic inputs to the SPN is simply delayed in Egr2; En $1^{\mathrm{CKO}}$ mice (Figures 2E-M).

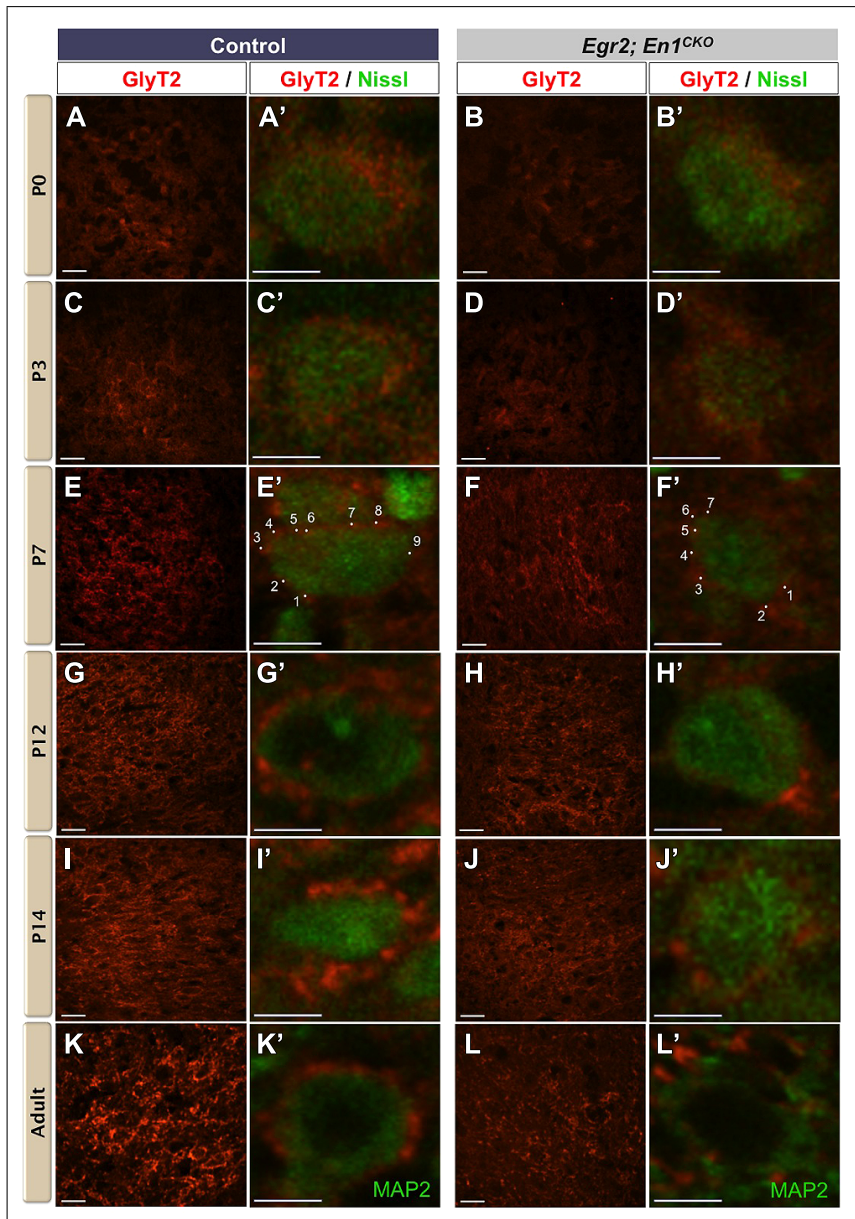

$\mathbf{M}$

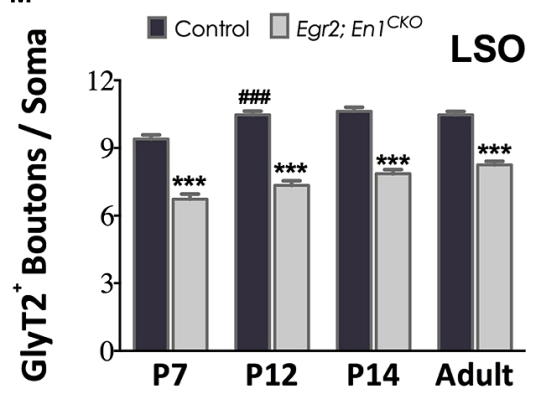

FIGURE 1 | Development of glycinergic innervation to the LSO of control and Egr2; En ${ }^{\text {CKO }}$ mice. Diffuse GlyT2 immunoreactivity was detected as early as PO in control (A, $\left.\mathbf{A}^{\prime}\right)$ and Egr2; En 1 CKO mice (B,, $\left.\mathbf{B}^{\prime}\right)$. Slight increases in staining intensity were seen in P3 control $\left(\mathbf{C}, \mathbf{C}^{\prime}\right)$ and Egr2; En $1^{\mathrm{CKO}}$ mice (D,D'). By P7, boutons located on LSO neuronal somata were easily discernible in both control $\left(\mathbf{E}, \mathbf{E}^{\prime}\right)$ and mutant mice $\left(\mathbf{F}, \mathbf{F}^{\prime}\right)$, albeit to a lesser extent in the latter. Individual boutons are shown with dots and numbers. By P12, levels of glycinergic innervation were increased in control mice $\left(\mathbf{G}, \mathbf{G}^{\prime}\right)$ but remained constant in Egr2; En1 ${ }^{C K O}$ mice $\left(\mathbf{H}, \mathbf{H}^{\prime}\right)$ compared to P7. Compared to controls $\left(\mathbf{I}, \mathbf{I}^{\prime}, \mathbf{K}, \mathbf{K}^{\prime}\right)$, Egr2; En1 ${ }^{C K O}$ mice had reduced glycinergic innervation at two weeks of age and in adulthood $\left.\mathbf{( J ,}, \mathbf{J}^{\prime}, \mathbf{L}, \mathbf{L}^{\prime}\right)$. The number of GlyT2+ boutons was counted in P7 and older mice when boutons were easily recognizable. Reductions in somatic GlyT2+ bouton number occurred in Egr2; En 1 CKO mice compared to control littermates at all ages examined (M). Data are represented as mean \pm SEM. Higher magnification images of individual neurons are shown in ( $\left.\mathbf{A}^{\prime} \mathbf{-}-\mathbf{L}^{\prime}\right)$. Scale bars: $20 \mu \mathrm{m}$ (A-D); $26 \mu \mathrm{m}$ (E-L); $8 \mu \mathrm{m}\left(\mathbf{A}^{\prime}-\mathbf{L}^{\prime}\right)$. ${ }^{*}{ }^{*} P<0.001$ vs. age-matched controls, \#\# $P<0.001$ vs. genotype-matched $P 7$ mice. 


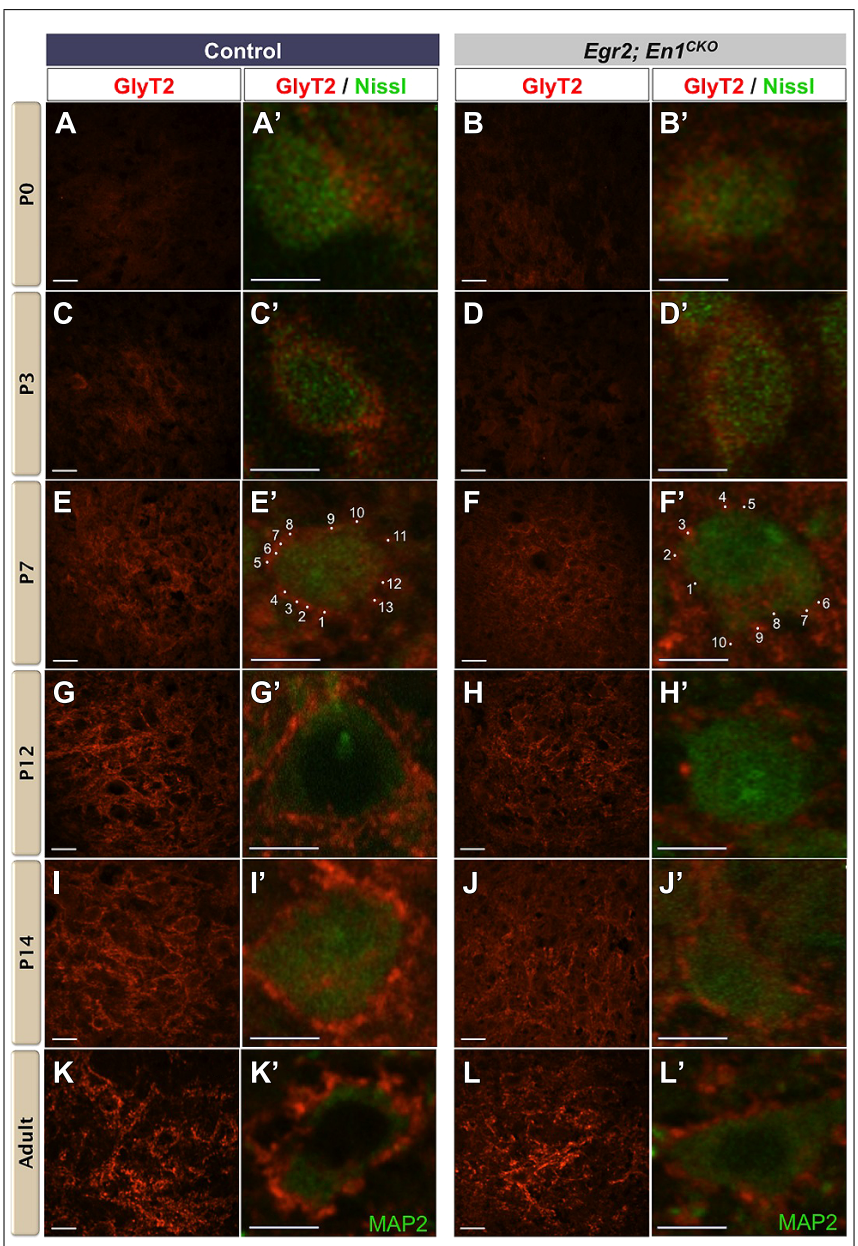

$\mathbf{M}$

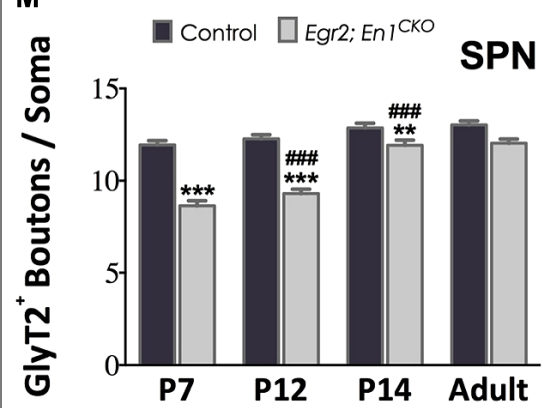

FIGURE 2 | Development of glycinergic innervation to the SPN of control and Egr2; En ${ }^{C K O}$ mice. Diffuse GlyT2 staining was present at birth in control $\left(\mathbf{A}, \mathbf{A}^{\prime}\right)$ and $E g r 2 ; E n 1^{C K O}$ mice (B, $\left.\mathbf{B}^{\prime}\right)$. Staining intensity increased by P3 in control (C, $\left.\mathbf{C}^{\prime}\right)$ and Egr2; En $1^{\text {CKO }}$ mice (D, $\left.\mathbf{D}^{\prime}\right)$. Identifiable boutons were first seen at P7 in control (E,E') and Egr2; En ${ }^{\mathrm{CKO}}\left(\mathbf{F}, \mathbf{F}^{\prime}\right)$ mice. Individual boutons are shown with dots and numbers. Staining intensity was also higher in control $\left(\mathbf{G}, \mathbf{G}^{\prime}\right)$ compared to Egr2; En 1 CKO mice $\left(\mathbf{H}, \mathbf{H}^{\prime}\right)$ at $\mathrm{P} 12$. However, levels were comparable in control and Egr2; En 1 CKO mice at P14 (I,I',J,J,') and adulthood (K,K',L,L'). (M) GlyT2+ bouton number located on SPN neuronal somata did not change from P7-adulthood in control mice. Bouton numbers were reduced at from P7-P14 in Egr2; En $1^{\mathrm{CKO}}$ mice, but were similar to controls in adulthood. Data are represented as mean \pm SEM. Higher magnification images of individual neurons are shown in ( $\left.\mathbf{A}^{\prime}-\mathbf{L}^{\prime}\right)$. Scale bars: $20 \mu \mathrm{m}$ (A-D); $26 \mu \mathrm{m}(\mathbf{E}-\mathbf{L}) ; 8 \mu \mathrm{m}$ (A'-L'). ${ }^{*} P<0.01,{ }^{*}{ }^{*} P<0.001$ vs. age-matched controls and \#\#\# $P<0.001$ vs. P7 or P12 Egr2; En1 ${ }^{\text {CKO mice }}$

\section{DENDRITIC LOCALIZATION OF GLYCINERGIC INNERVATION IS UNALTERED IN Egr2; En $1^{\text {CKO }}$ MICE}

We next examined whether $E g r 2$; $E n 1^{\mathrm{CKO}}$ mice exhibited alterations in glycinergic innervation of $\mathrm{LSO}$ and SPN neuron dendrites by co-immunostaining for GlyT2 and microtubule-associated protein 2 (MAP2; Figures $3 \mathrm{~A}-\mathrm{D}^{\prime \prime \prime}$ ). The overall distribution of boutons along the proximal $15 \mu \mathrm{m}$ of LSO and SPN neuron dendrites was similar in littermate control and Egr2; $E n 1^{\mathrm{CKO}}$ mice (Figures 3E-G). Furthermore, the number of boutons binned into $5 \mu \mathrm{m}$ segments up to $15 \mu \mathrm{m}$ from the cell soma was also similar (LSO - Control: $0-5 \mu \mathrm{m}-2.67 \pm 0.47,5-10 \mu \mathrm{m}-$ $2.58 \pm 0.36$, and $10-15 \mu \mathrm{m}-1.67 \pm 0.31 ; E g r 2 ; E n 1^{\mathrm{CKO}}$ mice: $0-5 \mu \mathrm{m}-1.58 \pm 0.40,5-10 \mu \mathrm{m}-2.17 \pm 0.42$, and $10-15 \mu \mathrm{m}$ $-2.17 \pm 0.27 ; P=0.10, P=0.65$, and $P=0.26$, respectively and SPN - Control: $0-5 \mu \mathrm{m}-2.00 \pm 0.35,5-10 \mu \mathrm{m}$ $-2.67 \pm 0.36$, and $10-15 \mu \mathrm{m}-2.92 \pm 0.29 ; \quad$ Egr $2 ; \quad$ En1 ${ }^{\text {СКO }}$ mice: $0-5 \mu \mathrm{m}-1.82 \pm 0.42,5-10 \mu \mathrm{m}-2.46 \pm 0.28$, and $10-15 \mu \mathrm{m}-2.27 \pm 0.36 ; P=0.50, P=0.87$, and $P=0.13$, respectively; Figures $\mathbf{3 H}, \mathbf{I}$ insets and data not shown). Taken together, these data indicate that the number and location of dendritic $\mathrm{GlyT}_{2}^{+}$boutons is similar in control and Egr2; En1 ${ }^{\mathrm{CKO}}$ mice.

\section{Egr2; En ${ }^{\text {CKO }}$ MICE HAVE REDUCED SOMATIC EXPRESSION OF THE GIYR $\alpha 1$ GLYCINE RECEPTOR SUBUNIT IN LSO BUT NOT SPN NEURONS}

We previously reported that glycinergic IPSC decay time constants were $>2.5$-fold slower in LSO and SPN neurons of Egr2; En1 ${ }^{\mathrm{CKO}}$ mice compared to littermate controls (Jalabi et al., 2013). We hypothesized that differences in the number or subunit composition of glycine receptors expressed by LSO and SPN neurons might explain these differences. Therefore, we examined expression patterns of two well-characterized glycine receptor subtypes, the adult-like isoform (GlyR $\alpha 1)$ and the purported developmental isoform (GlyR $\alpha 2$ ). Punctate GlyR $\alpha 1$ immunoreactivity was present in LSO and SPN neurons of both genotypes (Figures $\mathbf{4 A - H}$ ). However, the number of GlyR $\alpha 1+$ clusters/soma was significantly higher in LSO neurons of control vs. Egr2; $\mathrm{En} 1^{\mathrm{CKO}}$ mice $(23.78 \pm 1.07$ vs. $13.91 \pm 0.97 ; N=21-29$ soma from 4 nuclei/mouse, $N=2$ mice/genotype, $P<0.001$; Figure $4 \mathrm{I}$ ). No difference was found in SPN neurons (control: $24.03 \pm 1.85$ vs. Egr2; $E n 1^{\mathrm{CKO}}$ mice: $20.93 \pm 1.41 ; N=17-27$ soma from four nuclei/mouse, $N=2$ mice/genotype, $P=0.08$; Figure $4 J$ ). In both control and Egr2; En1 ${ }^{\mathrm{CKO}}$ mice, typical GlyR $\alpha 1$ rosettes (Hruskova et al., 2012) could be identified and glycinergic receptors were apposed to GlyT2 + boutons (Figures $4 \mathbf{A}^{\prime \prime \prime}, \mathbf{B}^{\prime \prime \prime}, \mathbf{C}^{\prime \prime \prime}, \mathbf{D}^{\prime \prime \prime}, \mathbf{G}^{\prime}, \mathbf{H}^{\prime}$ ). GlyR $\alpha 2$ expression was not present in LSO (Figures $4 \mathbf{K}-\mathbf{L}^{\prime \prime \prime}$ ) or SPN (data not shown) neurons in control or Egr2; En1 ${ }^{\mathrm{CKO}}$ mice. This suggests that a failure to switch to the adult isoform (fast decay kinetics) from the developmental isoform (slower decay kinetics) does not account for altered IPSC kinetics in these mice.

\section{DISCUSSION}

Our data demonstrate that glycinergic innervation measured by GlyT2 immunoreactivity in the mouse LSO and SPN follows a similar developmental time course to that seen in other rodents such as guinea pigs and rats (Wenthold et al., 1987; Helfert et al., 1989, 1992; Friauf et al., 1999). Gradual increases in GlyT2 expression 


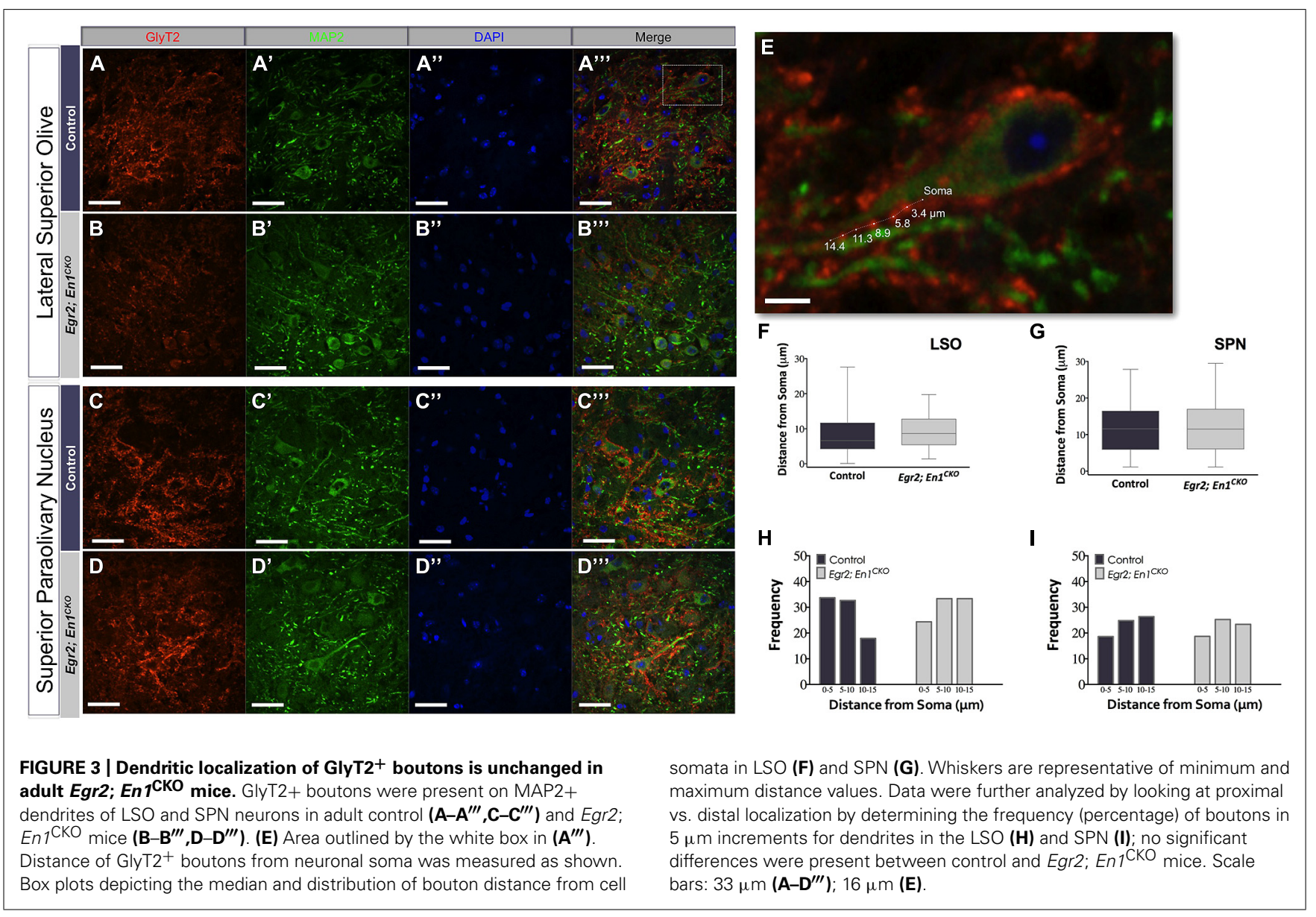

and the formation of distinct somatic boutons during the first postnatal week coincide with the timeframe of synaptic pruning and strengthening of connections arising from the MNTB during the transient excitatory period of these developing networks (Kim and Kandler, 2003). Adult-like GlyT2 expression occurs sooner in the SPN than in the LSO, and both mature in advance of hearing onset (Willott, 2001). This pattern coincides with the earlier functional maturation of SPN neurons demonstrated by their earlier switch from depolarizing (excitatory) to hyperpolarizing (inhibitory) glycinergic post-synaptic responses, which occurs by birth in the SPN but not until P3-P5 in the LSO (Kullmann and Kandler, 2001; Löhrke et al., 2005). One difference between rats and mice is that the intensity of GlyT2 immunoreactivity reaches maximum levels at P10 in the rat (Friauf et al., 1999), while in mice it is maximal in the adult (Figures $\mathbf{1} \mathbf{K}-\mathbf{L}^{\prime}$ and $\left.2 \mathrm{~K}-\mathrm{L}^{\prime}\right)$.

Our data provide insights into the development of glycinergic SOC innervation in the absence of MNTB neurons. In the LSO, the number of GlyT2+ boutons/soma increases at a similar rate from P7 to adulthood but is consistently 20-30\% lower in Egr2; $E n 1^{\mathrm{CKO}}$ than controls. This suggests that the developmental time course of GlyT2 immunoreactivity is similar in both genotypes. Conversely, glycinergic development is delayed in the SPN, as the number of glycinergic boutons/SPN neuron soma does not reach adult levels until P14 in Egr2; En1 ${ }^{\mathrm{CKO}}$ mice, 7 days after controls.
However, the number of boutons/soma is similar in adult Egr2; $E n 1^{\mathrm{CKO}}$ and littermate control mice, suggesting that development is simply delayed rather than permanently altered as it is in the LSO. GlyT2 function is theorized to influence the development of inhibitory networks in the SOC because its expression precedes synapse maturation in multiple central auditory regions (Kandler and Friauf, 1995; Ehrlich etal., 1998; Friauf et al., 1999). Thus, reduced levels of GlyT2 expression in the LSO and SPN of Egr2; $\mathrm{En} 1^{\mathrm{CKO}}$ mice during early postnatal development could contribute to persistent changes in glycinergic circuitry and function in these mice.

The number and distribution of GlyT2+ boutons on the dendrites of LSO and SPN neurons is similar in adult Egr2; En1 ${ }^{\mathrm{CKO}}$ mice and littermate controls (Figure 3). This is consistent with the interpretation that non-MNTB-derived glycinergic projections normally target the dendrites, and ectopically expands to LSO and SPN neuronal somata only in the absence of competition from MNTB-derived projections. Alternatively, this could occur if improper refinement and/or synaptic pruning of distally located boutons takes place in the absence of MNTB-derived projections. For example, developmentally regulated activity-dependent relocation of inhibitory inputs from dendrites to cell somata occurs in medial superior olive (MSO) neurons of animals with welldeveloped low frequency hearing (Kapfer et al., 2002); whether a similar process occurs in the LSO of animals that rely on 

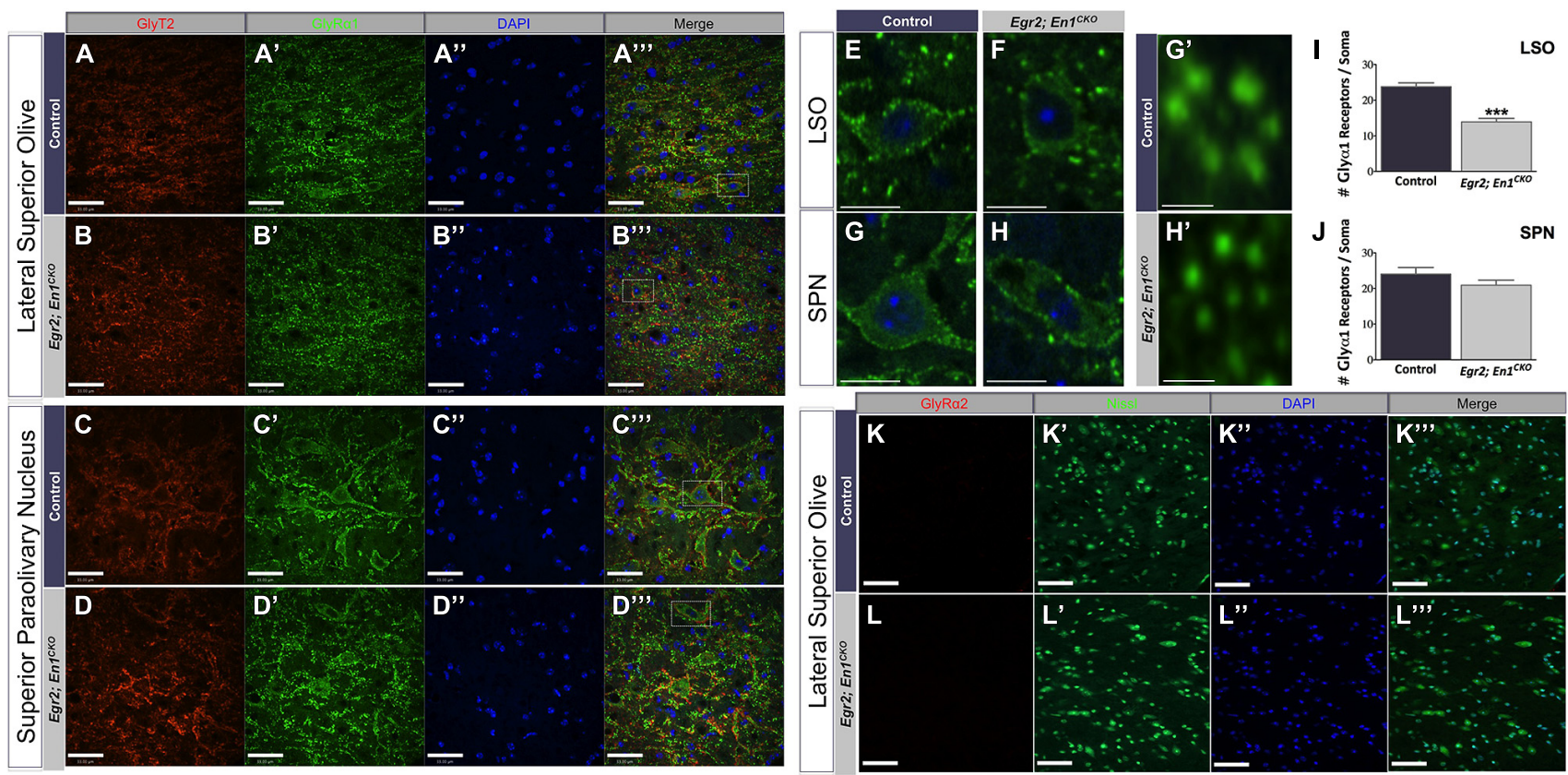

FIGURE 4 | Glycine receptor isoform expression patterns, but not receptor number, are similar in LSO and SPN neurons of adult control and Egr2; En ${ }^{\text {CKO }}$ mice. Adult control and Egr2; En1 ${ }^{C K O}$ mouse brain sections through the LSO $(\mathbf{A}, \mathbf{B})$ and SPN $(\mathbf{C}, \mathbf{D})$ were

immunostained for GlyT2 (A-D) and the glycine receptor isoform alpha 1 (GlyR $\left.\alpha 1 ; \mathbf{A}^{\prime}-\mathbf{D}^{\prime}\right)$. (E-H) Higher magnification images showing punctate staining on LSO (E,F) and SPN $(\mathbf{G}, \mathbf{H})$ neuronal somata and dendrites are shown in control $(\mathbf{E}, \mathbf{G})$ and $\operatorname{Egr} 2 ; \operatorname{En} 1 \mathrm{CKO}(\mathbf{F}, \mathbf{H})$ mice. $\left(\mathbf{G}^{\prime}, \mathbf{H}^{\prime}\right)$ High

high-frequency hearing (like the mouse) is not known. A third possibility is that MNTB- and non-MNTB-derived glycinergic inputs normally intermingle on cell somata and dendrites, and that the non-MNTB-derived innervation expands in both locations in the absence of MNTB neurons. Identification of the source of the nonMNTB-derived innervation followed by labeling of its projections is necessary to distinguish between these possibilities. Regardless, changes in glycinergic bouton localization cannot cause the altered IPSC kinetics seen in LSO and SPN neurons of Egr2; $E n 1^{\mathrm{CKO}}$ mice (Jalabi et al., 2013).

We also examined GlyR subunit expression in the LSO and SPN of adult control and Egr2; $E n 1^{\mathrm{CKO}}$ mice. Glycine receptors are multimeric proteins composed of 2 alpha and 3 beta subunits (Lynch, 2009; Dutertre et al., 2012; Yang et al., 2012). Alpha subunits contain the ligand binding pocket and come in four isoforms (GlyR $\alpha 1-\alpha 4$ ), each of which confers different functional channel properties (Pfeiffer et al., 1982). We focused on GlyR $\alpha 1$ and GlyR $\alpha 2$ because these receptors are expressed by developing and/or mature SOC neurons of other species (Friauf et al., 1997; Piechotta et al., 2001), and they confer fast and slow IPSC decay kinetics to the GlyR, respectively (Takahashi et al., 1992; Bormann et al., 1993; Singer et al., 1998; Weiss et al., 2008). Our finding that GlyR $\alpha 1$ was highly expressed by LSO and SPN neurons of adult mice agrees with previous studies in adult rats (Sato et al., 1995; Friauf et al., 1997; Piechotta et al., 2001). GlyR $\alpha 1$ expression was detected in the LSO of Egr2; En ${ }^{\mathrm{CKO}}$ mice, but the number of magnification images of typical GlyRa1 rosettes. Counts of GlyR $\alpha 1+$ puncta per LSO (I) or SPN (J) neuronal soma revealed decreased numbers in the LSO, but not SPN, of Egr2; En1 ${ }^{\mathrm{CKO}}$ compared to control mice. Data are represented as mean \pm SEM. Glycine receptor alpha 2 (GlyRa2) was not expressed by LSO neurons in adult control (K) or Egr2; En $1^{\mathrm{CKO}}$ mice (L). DAPI (A-D",K",L") and Nissl (K','ا') counterstains are also shown. Scale bars: $33 \mu \mathrm{m}(\mathbf{A}-\mathbf{D}, \mathbf{K}, \mathbf{L}) ; 12 \mu \mathrm{m}$ (E-H); $2.3 \mu \mathrm{m}\left(\mathbf{G}^{\prime}, \mathbf{H}^{\prime}\right)$. ${ }^{* *} P<0.001$ vs. control. receptor clusters per neuronal cell body was reduced compared to controls. This reduction, along with the reduced number of GlyT2+ boutons, may contribute to the decreased IPSC amplitudes seen in LSO neurons of these mice (Jalabi et al., 2013). Our hypothesis that maintained expression of GlyR $\alpha 2$, which is normally expressed only during embryonic and postnatal ages (Becker et al., 1988; Akagi et al., 1991; Malosio et al., 1991; Sato et al., 1995; Kungel and Friauf, 1997; Piechotta et al., 2001), might explain the aberrant IPSC decay kinetics proved to be incorrect as GlyR $\alpha 2$ was not expressed by LSO or SPN neurons in adult control or Egr2; En1 ${ }^{\mathrm{CKO}}$ mice. We did not examine GlyR $\alpha 4$ because it is minimally expressed in the CNS (Harvey et al., 2000) and therefore is unlikely to contribute to the altered electrophysiological responses seen in $\mathrm{Egr}_{2}$; $\mathrm{En}_{1}{ }^{\mathrm{CKO}}$ mice. Similarly, we did not examine $\beta$ subunit distribution as alterations in its expression are predicted to affect glycine receptor trafficking and clustering (Kneussel and Betz, 2000), which appear to be unaffected in Egr2; En1 ${ }^{\mathrm{CKO}}$ mice (Figures $4 \mathbf{E}^{\prime}, \mathbf{F}^{\prime}$ ). Future studies could examine GlyR $\alpha 3$ expression, which shows similar kinetics to GlyR $\alpha 1$ and is expressed in the auditory brainstem, albeit at lower levels (Sato et al., 1995).

Taken together, our findings demonstrate dynamic developmental reprogramming of the SOC glycinergic circuitry in the absence of the MNTB. Identifying the source(s) of this nonMNTB-derived innervation in Egr2; En1 ${ }^{\mathrm{CKO}}$ mice in conjunction with experiments to measure function and expression of receptors 
at critical developmental time points is necessary to clarify factors that lead to persistent changes. The striking ability of this system to compensate in the absence of the MNTB has potential clinical implications that might be important for understanding altered central auditory function in autism, where neuron number is lower in many SOC subnuclei (Rosenblum et al., 1980; Wong and Wong, 1991; Maziade et al., 2000; Kulesza, 2008; Kulesza et al., 2011), and in age-related hearing loss (Grimsley and Sivaramakrishnan, 2014).

\section{ACKNOWLEDGMENTS}

We are grateful for the assistance and insightful comments on the preparation of this manuscript provided by members of the Maricich Lab. We also extend thanks to Dr. Timothy Sanders at Children's Hospital of Pittsburgh (Pittsburgh, PA, USA) and his laboratory for the use of their confocal microscope, and to Dr. Gary Landreth at Case Western Reserve University for supplying laboratory space to Walid Jalabi. This work was supported by the Richard King Mellon Institute for Pediatric Research at the University of Pittsburgh (Stephen M. Maricich), the National Institute on Deafness and other Communication Disorders (NIDCD) of the National Institutes of Health under award number T32DC004199 NIH (Stefanie C. Altieri), and NIDCD F32DC011982 (Walid Jalabi).

\section{REFERENCES}

Adams, J. C., and Mugnaini, E. (1990). Immunocytochemical evidence for inhibitory and disinhibitory circuits in the superior olive. Hear. Res. 49, 281-298. doi: 10.1016/0378-5955(90)90109-3

Akagi, H., Hirai, K., and Hishinuma, F. (1991).Cloning of a glycine receptor subtype expressed in rat brain and spinal cord during a specific period of neuronal development. FEBS Lett. 281, 160-166. doi: 10.1016/0014-5793(91)80383-E

Aoki, E., Semba, R., Keino, H., Kato, K., and Kashiwamata, S. (1988). Glycinelike immunoreactivity in the rat auditory pathway. Brain Res. 442, 63-71. doi: 10.1016/0006-8993(88)91432-1

Becker, C. M., Hoch, W., and Betz, H. (1988). Glycine receptor heterogeneity in rat spinal cord during postnatal development. EMBO J. 7, 3717-3726.

Behrend, O., Brand, A., Kapfer, C., and Grothe, B. (2002). Auditory response properties in the superior paraolivary nucleus of the gerbil. J. Neurophysiol. 87, 2915-2928.

Bledsoe, S. C., Snead, C. R., Helfert, R. H., Prasad, V., Wenthold, R. J., and Altschuler, R. A. (1990). Immunocytochemical and lesion studies support the hypothesis that the projection from the medial nucleus of the trapezoid body to the lateral superior olive is glycinergic. Brain Res. 517, 189-194. doi: 10.1016/0006-8993(90)91025-C

Bormann, J., Rundström, N., Betz, H., and Langosch, D. (1993). Residues within transmembrane segment $\mathrm{M} 2$ determine chloride conductance of glycine receptor homo- and hetero-oligomers. EMBO J. 12, 3729-3737.

Boudreau, J. C., and Tsuchitani, C. (1968). Binaural interaction in the cat superior olive S segment. J. Neurophysiol. 31, 442-454. doi: 10.1121/1.2144209

Dehmel, S., Kopp-Scheinpflug, C., Dörrscheidt, G. J., and Rübsamen, R. (2002). Electrophysiological characterization of the superior paraolivary nucleus in the Mongolian gerbil. Hear. Res. 172, 18-36. doi: 10.1016/S0378-5955(02) 00353-2

Dutertre, S., Becker, C.-M., and Betz, H. (2012). Inhibitory glycine receptors: an update. J. Biol. Chem. 287, 40216-40223. doi: 10.1074/jbc.R112.408229

Ehret, G. (1976). Development of absolute auditory thresholds in the house mouse (Mus musculus). J. Am. Audiol. Soc. 1, 179-184.

Ehrlich, I., Ilic, V., Lohmann, C., and Friauf, E. (1998). Development of glycinergic transmission in organotypic cultures from auditory brain stem. Neuroreport 9, 2785-2790. doi: 10.1097/00001756-19980824 0-00019
Felix, R. A., Magnusson, A. K., and Berrebi, A. S. (2014). The superior paraolivary nucleus shapes temporal response properties of neurons in the inferior colliculus. Brain Struct. Funct. doi: 10.1007/s00429-014-0815-8 [Epub ahead of print].

Friauf, E., Aragón, C., Löhrke, S., Westenfelder, B., and Zafra, F. (1999). Developmental expression of the glycine transporter GLYT2 in the auditory system of rats suggests involvement in synapse maturation. J. Comp. Neurol. 412, 17-37. doi: 10.1002/(SICI) 1096-9861(19990913)412:1<17::AbreakID-CNE2>3.0.CO;2-E

Friauf, E., Hammerschmidt, B., and Kirsch, J. (1997). Development of adulttype inhibitory glycine receptors in the central auditory system of rats. J. Comp. Neurol. 385, 117-134. doi: 10.1002/(SICI) 1096-9861(19970818)385:1<117::AIDCNE7>3.0.CO;2-5

Friauf, E., and Ostwald, J. (1988). Divergent projections of physiologically characterized rat ventral cochlear nucleus neurons as shown by intra-axonal injection of horseradish peroxidase. Exp. Brain Res. 73, 263-284. doi: 10.1007/BF00248219

Grimsley, C. A., and Sivaramakrishnan, S. (2014). Postnatal developmental changes in the medial nucleus of the trapezoid body in a mouse model of auditory pathology. Neurosci. Lett. 559, 152-157. doi: 10.1016/j.neulet.2013.11.051

Harvey, R. J., Schmieden, V., Holst Von, A., Laube, B., Rohrer, H., and Betz, H. (2000). Glycine receptors containing the alpha4 subunit in the embryonic sympathetic nervous system, spinal cord and male genital ridge. Eur. J. Neurosci. 12, 994-1001. doi: 10.1046/j.1460-9568.2000.00993.x

Helfert, R. H., Bonneau, J. M., Wenthold, R. J., and Altschuler, R. A. (1989). GABA and glycine immunoreactivity in the guinea pig superior olivary complex. Brain Res. 501, 269-286. doi: 10.1016/0006-8993(89)90644-6

Helfert, R. H., Juiz, J. M., Bledsoe, S. C., Bonneau, J. M., Wenthold, R. J., and Altschuler, R. A. (1992). Patterns of glutamate, glycine, and GABA immunolabeling in four synaptic terminal classes in the lateral superior olive of the guinea pig. J. Comp. Neurol. 323, 305-325. doi: 10.1002/cne.903230302

Hruskova, B., Trojanova, J., Kulik, A., Kralikova, M., Pysanenko, K., Bures, Z., et al. (2012). Differential distribution of glycine receptor subtypes at the rat calyx of held synapse. J. Neurosci. 32, 17012-17024. doi: 10.1523/JNEUROSCI.154712.2012

Jalabi, W., Kopp-Scheinpflug, C., Allen, P. D., Schiavon, E., Digiacomo, R. R., Forsythe, I. D., etal. (2013). Sound localization ability and glycinergic innervation of the superior olivary complex persist after genetic deletion of the medial nucleus of the trapezoid body. J. Neurosci. 33, 15044-15049. doi: 10.1523/JNEUROSCI.2604-13.2013

Jursky, F., and Nelson, N. (1996). Developmental expression of the glycine transporters GLYT1 and GLYT2 in mouse brain. J. Neurochem. 67, 336-344. doi: 10.1046/j.1471-4159.1996.67010336.x

Kadner, A., and Berrebi, A. S. (2008). Encoding of temporal features of auditory stimuli in the medial nucleus of the trapezoid body and superior paraolivary nucleus of the rat. Neuroscience 151, 868-887. doi: 10.1016/j.neuroscience.2007.11.008

Kadner, A., Kulesza, R. J., and Berrebi, A. S. (2006). Neurons in the medial nucleus of the trapezoid body and superior paraolivary nucleus of the rat may play a role in sound duration coding. J. Neurophysiol. 95, 1499-1508. doi: 10.1152/jn.00902.2005

Kandler, K., Clause, A., and Noh, J. (2009). Tonotopic reorganization of developing auditory brainstem circuits. Nat. Neurosci. 12, 711-717. doi: 10.1038/nn.2332

Kandler, K., and Friauf, E. (1995). Development of glycinergic and glutamatergic synaptic transmission in the auditory brainstem of perinatal rats. J. Neurosci. 15, 6890-6904.

Kandler, K., and Gillespie, D. C. (2005). Developmental refinement of inhibitory sound-localization circuits. Trends Neurosci. 28, 290-296. doi: 10.1016/j.tins.2005.04.007

Kapfer, C., Seidl, A. H., Schweizer, H., and Grothe, B. (2002). Experience-dependent refinement of inhibitory inputs to auditory coincidence-detector neurons. Nat. Neurosci. 5, 247-253. doi: 10.1038/nn810

Kim, G., and Kandler, K. (2003). Elimination and strengthening of glycinergic/GABAergic connections during tonotopic map formation. Nat. Neurosci. 6, 282-290. doi: 10.1038/nn1015

Kneussel, M., and Betz, H. (2000). Clustering of inhibitory neurotransmitter receptors at developing postsynaptic sites: the membrane activation model. Trends Neurosci. 23, 429-435. doi: 10.1016/S0166-2236(00)01627-1

Kulesza, R. J. (2008). Cytoarchitecture of the human superior olivary complex: nuclei of the trapezoid body and posterior tier. Hear. Res. 241, 52-63. doi: 10.1016/j.heares.2008.04.010 
Kulesza, R. J., Kadner, A., and Berrebi, A. S. (2007). Distinct roles for glycine and GABA in shaping the response properties of neurons in the superior paraolivary nucleus of the rat. J. Neurophysiol. 97, 1610-1620. doi: 10.1152/jn.00 613.2006

Kulesza, R. J., Lukose, R., and Stevens, L. V. (2011). Malformation of the human superior olive in autistic spectrum disorders. Brain Res. 1367, 360-371. doi: 10.1016/j.brainres.2010.10.015

Kulesza, R. J., Spirou, G. A., and Berrebi, A. S. (2003). Physiological response properties of neurons in the superior paraolivary nucleus of the rat. J. Neurophysiol. 89, 2299-2312. doi: 10.1152/jn.00547.2002

Kullmann, P. H., and Kandler, K. (2001). Glycinergic/GABAergic synapses in the lateral superior olive are excitatory in neonatal C57Bl/6J mice. Brain Res. Dev. Brain Res. 131, 143-147. doi: 10.1016/S0165-3806(01)00271-1

Kungel, M., and Friauf, E. (1997). Physiology and pharmacology of native glycine receptors in developing rat auditory brainstem neurons. Brain Res. Dev. Brain Res. 102, 157-165. doi: 10.1016/S0165-3806(97)00087-4

Löhrke, S., Srinivasan, G., Oberhofer, M., Doncheva, E., and Friauf, E. (2005). Shift from depolarizing to hyperpolarizing glycine action occurs at different perinatal ages in superior olivary complex nuclei. Eur. J. Neurosci. 22, 2708-2722. doi 10.1111/j.1460-9568.2005.04465.x

Lynch, J. W. (2009). Native glycine receptor subtypes and their physiological roles. Neuropharmacology 56, 303-309. doi: 10.1016/j.neuropharm.2008.07.034

Malosio, M. L., Marquèze-Pouey, B., Kuhse, J., and Betz, H. (1991). Widespread expression of glycine receptor subunit mRNAs in the adult and developing rat brain. EMBO J. 10, 2401-2409.

Maziade, M., Mérette, C., Cayer, M., Roy, M. A., Szatmari, P., Côté, R., et al. (2000). Prolongation of brainstem auditory-evoked responses in autistic probands and their unaffected relatives. Arch. Gen. Psychiatry 57, 1077-1083. doi: 10.1001/archpsyc.57.11.1077

Moore, M. J., and Caspary, D. M. (1983). Strychnine blocks binaural inhibition in lateral superior olivary neurons. J. Neurosci. 3, 237-242.

Peyret, D., Campistron, G., Geffard, M., and Aran, J. M. (1987). Glycine immunoreactivity in the brainstem auditory and vestibular nuclei of the guinea pig. Acta Otolaryngol. 104, 71-76. doi: 10.3109/00016488709109049

Pfeiffer, F., Graham, D., and Betz, H. (1982). Purification by affinity chromatography of the glycine receptor of rat spinal cord. J. Biol. Chem. 257, 9389-9393.

Piechotta, K., Weth, F., Harvey, R. J., and Friauf, E. (2001). Localization of rat glycine receptor alphal and alpha2 subunit transcripts in the developing auditory brainstem. J. Comp. Neurol. 438, 336-352. doi: 10.1002/cne.1319

Rosenblum, S. M., Arick, J. R., Krug, D. A., Stubbs, E. G., Young, N. B., and Pelson, R. O. (1980). Auditory brainstem evoked responses in autistic children. J. Autism Dev. Disord. 10, 215-225. doi: 10.1007/BF02408472

Sanes, D. H., and Rubel, E. W. (1988). The ontogeny of inhibition and excitation in the gerbil lateral superior olive. J. Neurosci. 8, 682-700.

Sanes, D. H., and Siverls, V. (1991). Development and specificity of inhibitory terminal arborizations in the central nervous system. J. Neurobiol. 22, 837-854. doi: 10.1002/neu.480220805

Sato, K., Kuriyama, H., and Altschuler, R. A. (1995). Expression of glycine receptor subunits in the cochlear nucleus and superior olivary complex using non-radioactive in-situ hybridization. Hear. Res. 91, 7-18. doi: 10.1016/03785955(95)00156-5

Schofield, B. R. (1995). Projections from the cochlear nucleus to the superior paraolivary nucleus in guinea pigs. J. Comp. Neurol. 360, 135-149. doi: $10.1002 / \mathrm{cne} .903600110$

Sgaier, S. K., Lao, Z., Villanueva, M. P., Berenshteyn, F., Stephen, D., Turnbull, R. K., et al. (2007). Genetic subdivision of the tectum and cerebellum into functionally related regions based on differential sensitivity to engrailed proteins. Development 134, 2325-2335. doi: 10.1242/dev.000620
Singer, J. H., Talley, E. M., Bayliss, D. A., and Berger, A. J. (1998). Development of glycinergic synaptic transmission to rat brain stem motoneurons. J. Neurophysiol. 80, 2608-2620.

Spangler, K. M., Warr, W. B., and Henkel, C. K. (1985). The projections of principal cells of the medial nucleus of the trapezoid body in the cat. J. Comp. Neurol. 238, 249-262. doi: 10.1002/cne.902380302

Srinivasan, G., Friauf, E., and Löhrke, S. (2004). Functional glutamatergic and glycinergic inputs to several superior olivary nuclei of the rat revealed by optical imaging. Neuroscience 128, 617-634. doi: 10.1016/j.neuroscience.2004.06.012

Takahashi, T., Momiyama, A., Hirai, K., Hishinuma, F., and Akagi, H. (1992). Functional correlation of fetal and adult forms of glycine receptors with developmental changes in inhibitory synaptic receptor channels. Neuron 9, 1155-1161. doi: 10.1016/0896-6273(92)90073-M

Thompson, A. M., and Thompson, G. C. (1991). Projections from the posteroventral cochlear nucleus to the superior olivary complex in guinea pig: light and EM observations with the PHA-L method. J. Comp. Neurol. 311, 495-508. doi: $10.1002 / \mathrm{cne} .903110405$

Voiculescu, O., Charnay, P., and Schneider-Maunoury, S. (2000). Expression pattern of a Krox-20/Cre knock-in allele in the developing hindbrain, bones, and peripheral nervous system. Genesis 26, 123-126. doi: 10.1002/(SICI)1526968X(200002)26:2<123::AID-GENE7>3.0.CO;2-O

Weiss, J., O'Sullivan, G. A., Heinze, L., Chen, H.-X., Betz, H., and Wässle, H. (2008). Glycinergic input of small-field amacrine cells in the retinas of wildtype and glycine receptor deficient mice. Mol. Cell. Neurosci. 37, 40-55. doi: 10.1016/j.mcn.2007.08.012

Wenthold, R. J., Huie, D., Altschuler, R. A., and Reeks, K. A. (1987). Glycine immunoreactivity localized in the cochlear nucleus and superior olivary complex. Neuroscience 22, 897-912. doi: 10.1016/0306-4522(87)92968-X

Willott, J. F. (2001). Handbook of Mouse Auditory Research. Boca Raton, FL: CRC Press.

Wong, V., and Wong, S. N. (1991). Brainstem auditory evoked potential study in children with autistic disorder. J. Autism Dev. Disord. 21, 329-340. doi: $10.1201 / 9781420038736$

Wu, S. H., and Kelly, J. B. (1991). Physiological properties of neurons in the mouse superior olive: membrane characteristics and postsynaptic responses studied in vitro. J. Neurophysiol. 65, 230-246. doi: 10.1007/BF02207329

Wu, S. H., and Kelly, J. B. (1992). Synaptic pharmacology of the superior olivary complex studied in mouse brain slice. J. Neurosci. 12, 3084-3097.

Wu, S. H., and Kelly, J. B. (1995). Inhibition in the superior olivary complex: pharmacological evidence from mouse brain slice. J. Neurophysiol. 73, 256-269.

Yang, Z., Taran, E., Webb, T. I., and Lynch, J. W. (2012). Stoichiometry and subunit arrangement of $\alpha 1 \beta$ glycine receptors as determined by atomic force microscopy. Biochemistry 51, 5229-5231. doi: 10.1021/bi300063m

Conflict of Interest Statement: The authors declare that the research was conducted in the absence of any commercial or financial relationships that could be construed as a potential conflict of interest.

Received: 31 July 2014; accepted: 21 August 2014; published online: 12 September 2014 Citation: Altieri SC, Zhao T, Jalabi W and Maricich SM (2014) Development of glycinergic innervation to the murine LSO and SPN in the presence and absence of the MNTB. Front. Neural Circuits 8:109. doi: 10.3389/fncir.2014.00109

This article was submitted to the journal Frontiers in Neural Circuits.

Copyright (c) 2014 Altieri, Zhao, Jalabi and Maricich. This is an open-access article distributed under the terms of the Creative Commons Attribution License (CC BY). The use, distribution or reproduction in other forums is permitted, provided the original author(s) or licensor are credited and that the original publication in this journal is cited, in accordance with accepted academic practice. No use, distribution or reproduction is permitted which does not comply with these terms. 